\title{
Lumped Parameter Modelling in Femoral Popliteal Artery for Normal and Severe Conditions
}

\author{
Asrizan Kaha ${ }^{1}$, Ishkrizat Taib ${ }^{1, *}$, Muhammad Sufyan Amir Paisal, Ahmad Mubarak Tajul \\ Arifin $^{1}$, Al Emran Ismail ${ }^{1}$, Norzelawati Asmuin', Reazul Haq Abdul Haq ${ }^{2}$, Surapong \\ Chatpun $^{3}$, Takahisa Yamamoto ${ }^{4}$, Kahar Osman ${ }^{5}$
}

${ }^{1}$ Flow Simulation and Turbulence Focus Group, Faculty of Mechanical and Manufacturing Engineering, Universiti Tun Hussein Onn Malaysia, Batu Pahat 86400, Johor, MALAYSIA

${ }^{2}$ Additive Manufacturing Research Group, Faculty of Mechanical and Manufacturing Engineering, Universiti Tun Hussein Onn Malaysia, Batu Pahat 86400, Johor, MALAYSIA

${ }^{3}$ Faculty of Medicine, Prince of Songkhla University, THAILAND

${ }^{4}$ Department of Mechanical Engineering, National Institute of Technology, Gifu College, JAPAN

${ }^{5}$ Faculty of Biosciences and Medical Engineering, Universiti Teknologi Malaysia, Skudai 81310 Johor, MALAYSIA

Received 14 August 2018; accepted 3 September 2018, available online 30 October 2018

\begin{abstract}
Development of numerical technique would be benefited to diagnose the biological structure especially in femoropopliteal artery. Blood circulatory system and heart hemodynamic performance can be simulated by applying lumped parameter method. Thus, this study aims to develop numerical modelling in femoropopliteal artery by constructing an electric analog model to the system. Three different cases have been considered in this study; normal blood condition, aneurysm and atherosclerosis conditions. Normal blood condition is also analysed as a basis study of comparison between aneurysm and atherosclerosis conditions. The electrical analog model with 3 nodes and terminal load at the end of this model are proposed. This algorithm is then verified against numerical data simulated using commercial software. The study shows that normal and abnormal conditions effect instantaneously to pressure and flow waveforms. The result shows that the highest peak pressure is shown in atherosclerosis condition about $3.2 \times 10^{5} \mathrm{~Pa}$ as compared to normal and aneurysm conditions which obtained about $1.7 \times 10^{4} \mathrm{~Pa}$ and $0.1 \times 10^{4} \mathrm{~Pa}$, respectively. On the other hand, the flow resistance increase about 16 fold as the radius in aneurysm at $3.0 \mathrm{~mm}$ is reduced to $1.4 \mathrm{~mm}$ for the aneurysm condition. Therefore, the aneurysm condition in the second segment shows the highest flow rate about $3.0 \times 10^{-3} \mathrm{~m}^{3} / \mathrm{s}$ as compared to the other conditions. In conclusion, the obtained waveform propagation from the linear analysis of the lumped parameter modelling shows that the periodic mean pressures and flow rate distributions in large arteries are highly depend on the resistances and the compliances. The quantitative variations of blood pressure and flow waveforms along the arterial of femoral popliteal artery from this model followed clinical trends as the normal condition show a stable pressure and flow rate obtained compare to the atherosclerosis and aneurysm condition.
\end{abstract}

Keywords: femoral popliteal artery, lumped parameter, atherosclerosis, aneurysm, 0-dimensional model, electrical analog model.

\section{Introduction}

Cardiovascular system is divided into two classes based on mathematical formulation. There are distributed which is $1 \mathrm{D}$ and $2 \mathrm{D}$ and lumped parameter which is $0 \mathrm{D}$. In lumped parameter, 3 elements are considered in terms of resistance $(\mathrm{R})$, inductor $(\mathrm{L})$ and capacitor $(\mathrm{C})[1]$. Usually, to understand more and details about the relationship between pressure and flow rate, the researcher have to used $0 \mathrm{D}$ model which is lumped parameter mathematical model in human cardiovascular system. [2, 3, 4-6, 7-9]. Table 1 show the analogy of electrical element to the blood vessel. Flow behaviour in the femoral popliteal artery is investigated by using lumped parameter to obtain a real data of the pressure flow rate. The data involve the non-blockage femoral popliteal artery and blockage femoral popliteal artery caused by decomposition of fat that disturbing the blood supply to the body called atherosclerosis [10, 11]. This project also includes the enlargement or bulging of an artery wall (aneurysm). Lumped parameter model is in common use for studying the factors that affect the pressure and flow waveforms. A lumped parameter model is one in which the continuous variation of the system's state variables in space is represented by a finite number of variables, defined at special points called nodes. The lumped element model of electronic circuits makes the simplifying assumption that the attributes of the circuit, resistance, capacitance, inductance, and gain, are concentrated into idealized electrical components; 
resistors, capacitors, and inductors, etc. joined by a network of perfectly conducting wires.

Table 1: Electrical appliance and the analogy in blood vessel [12].

\begin{tabular}{cc}
\hline Element & Analogy \\
\hline Voltage, $V$ & Pressure difference, $d P$ \\
Current, $I$ & Flow rate, $q$ \\
Resistance, $R$ & Viscous flow resistance \\
Inductance, $L$ & Blood inertia \\
Compliance, $C$ & Compliance of the vessel \\
Impedance, $Z$ & Terminal boundary \\
& resistance \\
\hline
\end{tabular}

\section{Methodology}

\subsection{Identification of the arterial model}

Figure 1, Figure 2 and Figure 3 show several alternative developments of the modelling of flow through any vessel or tube based on that electrical analog model. It is consist of vessel load with three segments and terminal load with only one segment. The subscript $\mathrm{V}$ represents the properties of the blood vessel while subscript $\mathrm{L}$ represents the properties of the terminating load.

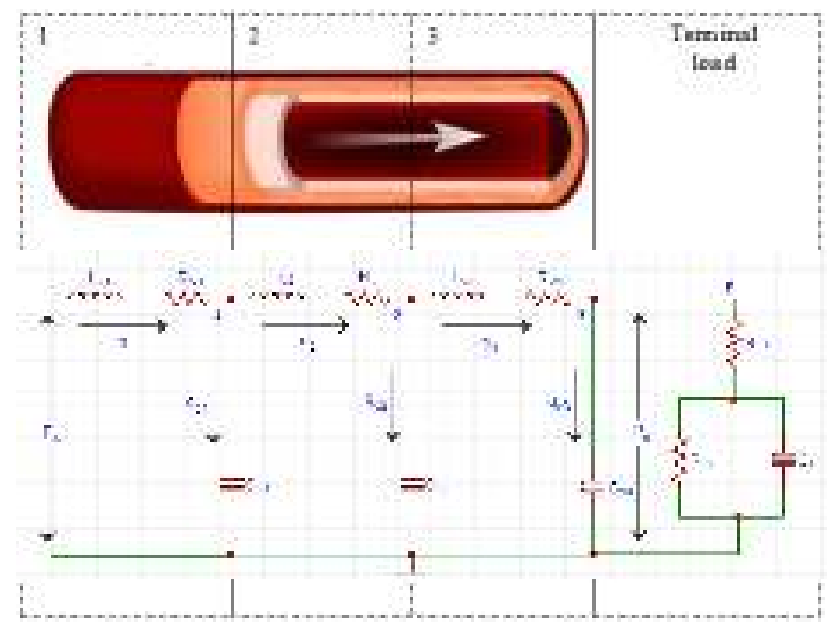

Fig. 1: Electric analog model for normal.

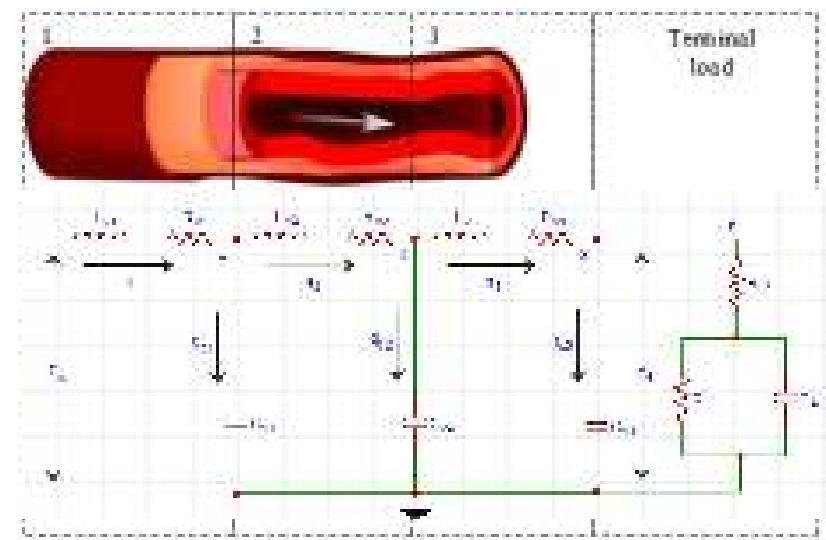

Fig. 2: Electric analog model for atherosclerosis.

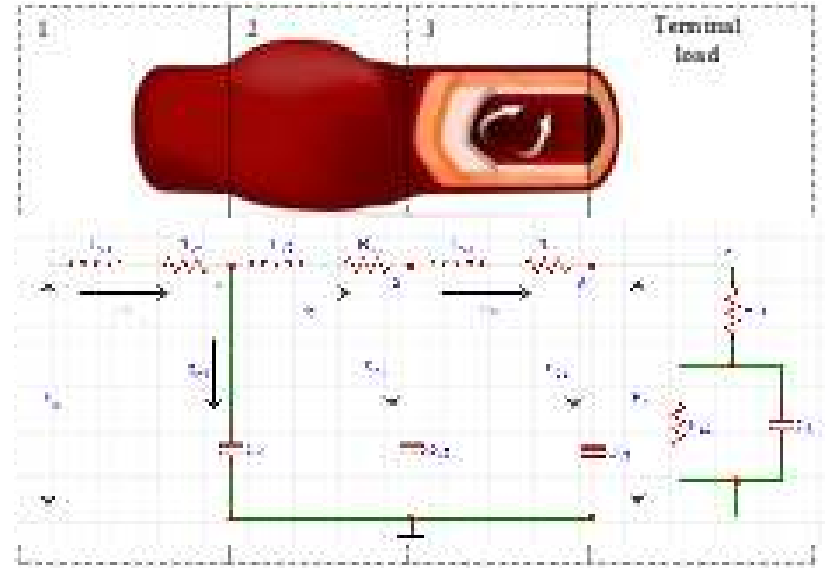

Fig. 3: Electric analog model for aneurysm.

\subsection{The development uses of Kirchoff voltage (KVL) and current law (KCL)}

The total voltage across the set of passive components is always equal and opposite to the source voltage. This means that the sum of the voltage differences across all the circuit elements (including the source) is always zero. Kirchhoff voltage law (KVL) equation on femoral popliteal artery electric analog model:

$$
\frac{d P_{R V}}{d t}=P_{0} \frac{R_{V}}{L_{V}}-P_{1} \frac{R_{V}}{L_{V}}+P_{R V} \frac{R_{V}}{L_{V}}
$$

The total current flowing into any DC circuit node is called a branch point. The value current enter the branch is always the same as the total current flowing out of the node. Kirchhoff current law (KCL) equation on femoral popliteal artery electric analog model:

Node 1, 2, 3: $\quad \frac{d P_{1}}{d t}=\frac{P_{R V}}{C_{V} R_{V}}-\frac{P_{1}}{C_{V} R_{L 1}}+\frac{P_{e}}{C_{V} R_{L 1}}$

Terminal load: $\frac{d P_{e}}{d t}=\frac{P_{1}}{R_{L 1} C_{L}}-\frac{P_{e}\left(R_{L 2}+R_{L 1}\right)}{C_{L} R_{L 1} R_{L 2}}$

From all equations, matrix $[\mathrm{A}]$ and $\{\mathrm{b}\}$ are constructed as following: 


$$
\begin{array}{ccccccc}
-\frac{R_{V 1}}{L_{V 1}} & 0 & 0 & -\frac{R_{V 1}}{L_{V 1}} & 0 & 0 & 0 \\
0 & -\frac{R_{V 2}}{L_{V 2}} & 0 & \frac{R_{V 2}}{L_{V 2}} & -\frac{R_{V 2}}{L_{V 2}} & 0 & 0 \\
0 & 0 & -\frac{R_{V 3}}{L_{V 3}} & 0 & \frac{R_{V 3}}{L_{V 3}} & -\frac{R_{V 3}}{L_{V 3}} & 0 \\
\frac{1}{C_{V 1} R_{V 1}} & -\frac{1}{C_{V 1} R_{V 2}} & 0 & 0 & 0 & 0 & 0 \\
0 & \frac{1}{C_{V 2} R_{V 2}} & -\frac{1}{C_{V 2} R_{V 3}} & 0 & 0 & 0 & 0 \\
0 & 0 & \frac{1}{C_{V 3} R_{V 3}} & -\frac{1}{C_{V 3} R_{L 1}} & 0 & 0 & \frac{1}{C_{V 3} R_{L 1}} \\
0 & 0 & \frac{1}{C_{L} R_{L 1}} \\
0 & {\left[\begin{array}{c}
0 \\
\frac{R_{V 1}}{L_{V 1}} \\
\frac{R_{V 2}}{C_{L} R_{L 1} R_{L 2}}
\end{array}\right]} \\
\{ & {\left[\begin{array}{c}
L_{V 2} \\
\frac{R_{V 3}}{L_{V 3}} \\
0 \\
0 \\
0 \\
0 \\
0
\end{array}\right]}
\end{array}
$$

Note that,

$P=$ pressure

$R_{v}=$ vessel resistance

$C_{v}=$ vessel capacitance

number $=$ node at $n^{\text {th }}$ segment

The subscript $\mathrm{V}$ represent properties of the blood vessel that we are modelling, the subscript $\mathrm{L}$ represent properties of the terminating load and e indicates the end load.

\subsection{Establish the harmonic motion}

Let the harmonic forcing function be represented by one harmonic at a time, such as $a_{n} \cos (n \omega t)$. In femoral popliteal artery model, there is but one harmonic term, so $n=1$. The differential equation is:

$$
\begin{gathered}
\left\{C_{1}\right\}=\left(\omega I+\frac{[A]}{\omega}\right)^{-1}\{b\} a_{1} \\
\left\{C_{2}\right\}=-\frac{[A]\left\{C_{1}\right\}}{\omega}
\end{gathered}
$$

\subsection{Flow rate solution} and $\{\mathrm{P}\}$

Then, the flow rate result obtain by multiple of $[R]$ 


$$
\begin{aligned}
& \{Q\}=[R]\{P\} \\
& {\left[\begin{array}{c}
q_{1} \\
q_{c 1} \\
q_{2} \\
q_{c 2} \\
q_{3} \\
q_{c 3} \\
q_{R L 1} \\
q_{R L 2} \\
q_{c L}
\end{array}\right]=\left[\begin{array}{ccccccc}
-\frac{R_{V 1}}{L_{V 1}} & 0 & 0 & -\frac{R_{V 1}}{L_{V 1}} & 0 & 0 & 0 \\
0 & -\frac{R_{V 2}}{L_{V 2}} & 0 & \frac{R_{V 2}}{L_{V 2}} & -\frac{R_{V 2}}{L_{V 2}} & 0 & 0 \\
0 & 0 & -\frac{R_{V 3}}{L_{V 3}} & 0 & \frac{R_{V 3}}{L_{V 3}} & -\frac{R_{V 3}}{L_{V 3}} & 0 \\
\frac{1}{C_{V 1} R_{V 1}} & -\frac{1}{C_{V 1} R_{V 2}} & 0 & 0 & 0 & 0 & 0 \\
0 & \frac{1}{C_{V 2} R_{V 2}} & -\frac{1}{C_{V 2} R_{V 3}} & 0 & 0 & 0 & 0 \\
0 & 0 & \frac{1}{C_{V 3} R_{V 3}} & -\frac{1}{C_{V 3} R_{L 1}} & 0 & 0 & \frac{1}{C_{V 3} R_{L 1}} \\
0 & 0 & 0 & \frac{1}{C_{L} R_{L 1}} & 0 & 0 & -\frac{R_{L 1}+R_{L 2}}{C_{L} R_{L 1} R_{L 2}}
\end{array}\right]\left[\begin{array}{c}
P_{R V 1} \\
P_{R V 2} \\
P_{R V 3} \\
P_{1} \\
P_{2} \\
P_{3} \\
P_{e}
\end{array}\right]}
\end{aligned}
$$

\subsection{Numerical solver}

MATLAB is an anonymous function. An anonymous function is like an inline function in traditional programming languages, defined within a single MATLAB statement. It consists of a single MATLAB expression and any number of input and output arguments. As the model under consideration, the MATLAB built in solvers were used to solve the model equations. The MATLAB solver is very useful to get a reasonable measure of sensitivity analysis with affordable computational cost.

\section{Results and Discussion}

\subsection{Characteristic and mean flow solution of femoral popliteal artery}

Table 2 shows the physical properties of femoral popliteal artery. In a flow distributions network that progresses from a blood vessel, the frequency, density, and dynamic viscosity are the same throughout the network. The fluctuating pressure, $a_{1}$ refer to the difference between systolic and diastolic blood pressure while blood frequency assumed to be $1 \mathrm{~Hz}$ or 6.28 rads- 1 .

Table 2: Characteristics of femoral popliteal artery.

\begin{tabular}{ccc}
\hline No & $\begin{array}{c}\text { Characteristics of } \\
\text { normal femoral } \\
\text { popliteal artery }\end{array}$ & Value \\
\hline 1. & Radius, R & $3.5 \mathrm{~mm}$ \\
2. & Length, L & $9.4 \mathrm{~cm}$ \\
3. & Thickness, $\mathrm{h}$ & $0.9 \times 10^{-3} \mathrm{~m}$ \\
4. & Density, $\rho$ & $1050 \mathrm{Ns} / \mathrm{m}^{3}$ \\
5. & Viscosity, $\mu$ & $0.0049 \mathrm{Ns} / \mathrm{m}^{2}$ \\
6. & Volume flow rate, $q$ & $2.88 \times 10^{-6} \mathrm{~m}^{3} / \mathrm{s}$ \\
6. & Mean pressure, $\mathrm{a}_{0}$ & $13097 \mathrm{~Pa}$ \\
7. & Fluctuating press, $\mathrm{a}_{1}$ & $8973 \mathrm{~Pa}$ \\
\hline
\end{tabular}

The result in Table 3 shows the value of mean flow solution which is the result of resistance, inductance and capacitance value in both vessel and terminal load in electrical analog model. The values of resistance and capacitance in vessel load are obtained from the parameter of varying solution while the terminal load is obtained from the impedance relationship in the terminal load.

Table 3: Mean flow solution of femoral popliteal artery.

\begin{tabular}{ccc}
\hline No & Mean flow & Value \\
\hline 1. & Angular frequency, $\omega$ & $6.28 \mathrm{rads}^{-1}$ \\
2. & Womersley number, $\alpha$ & 4.06 \\
3. & Resistance coefficient, $c_{v}$ & 1.27 \\
4. & Inertance coefficient, $c_{u}$ & 1.18 \\
5. & Resistance, $R_{V 1}, R_{V 2}, R_{V 3}$ & $1.0 \times 10^{7} \mathrm{Ns}^{5} \mathrm{~m}^{5}$ \\
6. & Inductance, $L_{V 1}, L_{V 2}, L_{V 3}$ & $3.026 \times 10^{6} \mathrm{Ns}^{2} / \mathrm{m}^{5}$ \\
7. & Capacitance, $C_{V 1}, C_{V 2}$, & $3.52 \times 10^{-12} \mathrm{~m}^{5} / \mathrm{N}$ \\
8. & First resistance terminal \\
load, $R_{L 1, \text { normal }}$ & $1.2486 \times 10^{7} \mathrm{Ns} / \mathrm{m}$ \\
9. & Second resistance & $4.536 \times 10^{9} \mathrm{Ns} / \mathrm{m}^{5}$ \\
10. & Capacitance terminal & $5.11 \times 10^{-9} \mathrm{~m}^{5} / \mathrm{N}$ \\
\hline
\end{tabular}

\subsection{Pressure rate of normal condition}

Pressure rate wave propagation as shown in Figure 4 are the difference rate of data obtain between the initial pressure and node 1 which is $P_{1}$ and the pressure rate across the vessel resistance for segment 1 . The value is slightly higher at $P_{R V}$ about $1.3 \times 10^{4} \mathrm{~Pa}$ and lowers at $P_{1}$ about $1.2 \times 10^{4} \mathrm{~Pa}$. This is because of the low fluid resistance of the vessel compare to the total resistance at the first segment. As the blood flow continuously to the second segment shown in Figure 4 (b), the pressure rate was not changed as the vessel resistance for the normal condition are still the same at this segment but decreasing to $0.4 \times 10^{4} \mathrm{~Pa}$ for $P_{R V 2}$. Figure 4 (c) shows the pressure rate at segment 3 . The wave propagation on the $P_{3}$ and $P_{R V}$ show the significant value with previous segment which are $1.0 \times 10^{4} \mathrm{~Pa}$ and $0.4 \times 10^{4} \mathrm{~Pa}$. At the terminal load, the $P_{e}$ has higher value as the fluid resistance in this load contains two resistors in series position. 


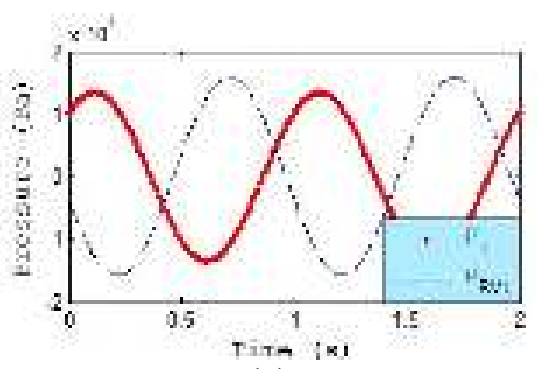

(a)

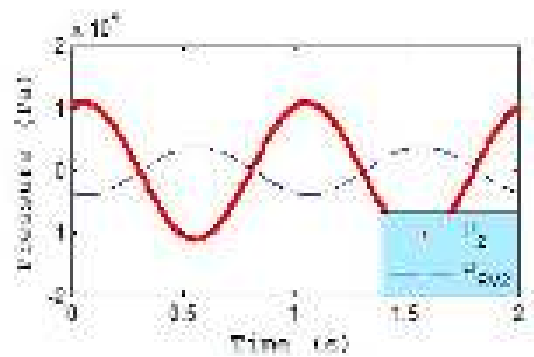

(b)

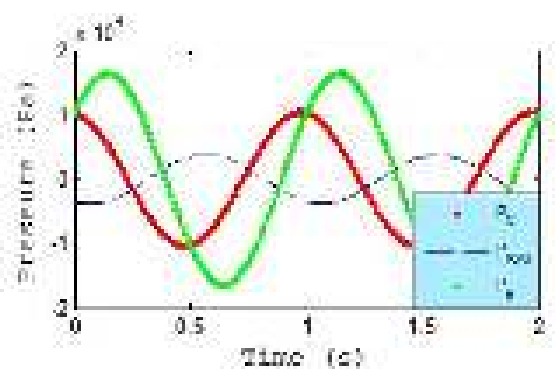

(c)

Fig. 4: Pressure rate of normal condition at (a) first segment (b) second segment (c) third and terminal segment.

\subsection{Flow rate of normal condition}

Figure 5 (a) shows the flow rate wave propagation in the first segment. The values of $q_{1}$ are slightly more than $q_{c 1}$ at $0.1 \times 10^{4} \mathrm{~Pa}$ from $q_{1}$ which produce $1.3 \times 10^{-3} \mathrm{~m}^{3} / \mathrm{s}$. This is because of the value of inductance, $L_{v 1}$ and fluid resistance, $R_{V 1}$ which element that the flow of $q_{1}$ move across is not too much difference with the capacitance value, $C_{V 1}$. The values of $q_{2}$ are totally different compared to the $q_{c 2}$ which gives $4 \times 10^{-4} \mathrm{~m}^{3} / \mathrm{s}$. In Figure $5(\mathrm{~b})$, flow at $q_{c 2}$ is approaching to zero because of a low storage of fluid in this artery segment as it experience the pulsatile flow while the flow across the capacitor in segment 2 which is $C_{V 2}$. As we can see in Figure 5 (c), the flow rate values of $q_{3}$ are decreasing to $1.0 \times 10^{-3} \mathrm{~m}^{3} / \mathrm{s}$ from the previous segment. However, the flow rate waveform $q_{c 3}$ in the third segment increases drastically as compared to the flow rate waveform of $q_{c 2}$ in the second segment. At the terminal load, the values are the same for flow rate $q_{R L 1}$ and $q_{c L}$ which is $1.1 \times 10^{-3} \mathrm{~m}^{3} / \mathrm{s}$. The $q_{R L 2}$ flow rate wave show the values almost reaching to zero as it pass through the second resistor at the terminal load.

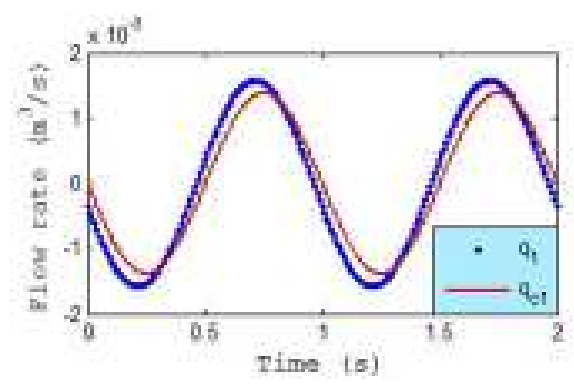

(a)

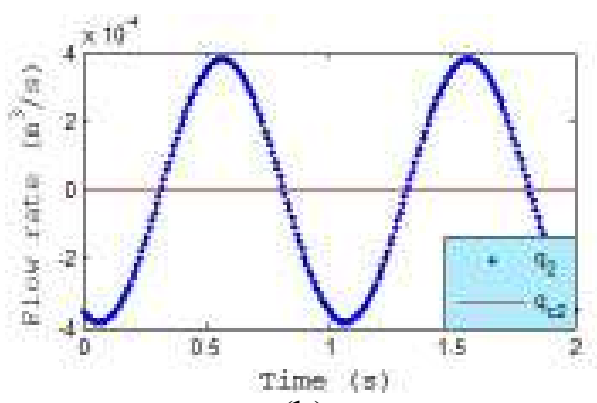

(b)

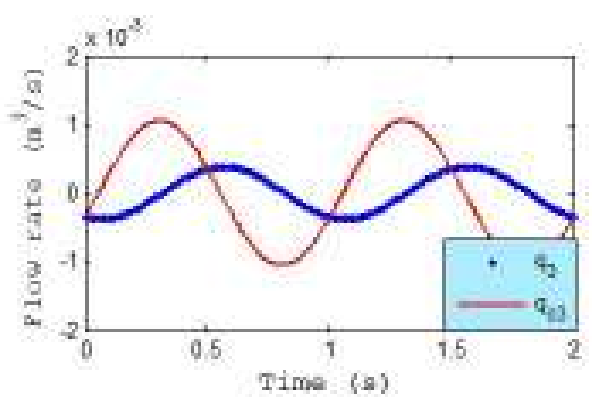

(c)

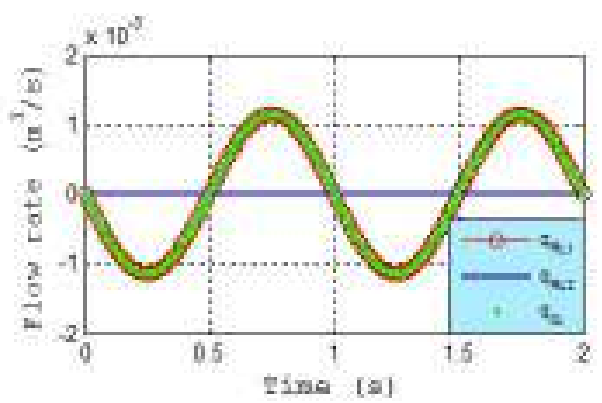

(d)

Fig. 5: Flow rate of normal condition at (a) first segment (b) second segment (c) third segment and (d) terminal segment.

\subsection{Characteristic and mean flow solution of femoral popliteal artery in abnormal condition}

At the first and third segment for atherosclerosis and aneurysm conditions, the diameter and other 
characteristics of femoral popliteal artery are maintained. Therefore, the values for mean flow solution are the same with the normal one. For the second segment in atherosclerosis, the diameter is decreased to $1.4 \mathrm{~mm}$ in order to analyse the effect of this abnormal disease which is atherosclerosis to the pressure and flow rate in the femoral popliteal artery. The results obtained are shown in Table 3. While the second segment in aneurysm, the diameter is increased to $30 \mathrm{~mm}$. The effect of this abnormal disease which is aneurysm to the pressure and flow rate in the femoral popliteal artery are shown in Table 4.

Table 3: Mean flow solution of atherosclerosis.

\begin{tabular}{|c|c|c|}
\hline No. & Mean flow & Value \\
\hline 1. & Angular frequency, $\omega$ & $6.28 \mathrm{rads}^{-1}$ \\
\hline 2. & Womersley number, $\alpha_{2}$ & 1.624 \\
\hline 3. & $\begin{array}{l}\text { Resistance coefficient, } \\
c_{v 2}\end{array}$ & 1.02 \\
\hline 4. & Inertance coefficient, $c_{u 2}$ & 1.30 \\
\hline 5. & $\begin{array}{c}\text { Resistance vessel load, } \\
R_{V 2}\end{array}$ & $3.114 \times 10^{8} \mathrm{Ns} / \mathrm{m}^{5}$ \\
\hline 6. & $\begin{array}{l}\text { Inductance vessel load, } \\
\qquad L_{V 2}\end{array}$ & $\begin{array}{l}2.084 \times 10^{7} \\
N s^{2} / m^{5}\end{array}$ \\
\hline 7. & $\begin{array}{c}\text { Capacitance vessel load, } \\
\qquad C_{V 2}\end{array}$ & $1.148 \times 10^{-7} \mathrm{~m}^{5} / \mathrm{N}$ \\
\hline 8. & $\begin{array}{l}\text { First resistance terminal } \\
\text { load, } R_{L 1, \text { stenosis }}\end{array}$ & $3.8175 \times 10^{7} \mathrm{Ns} / \mathrm{m}$ \\
\hline 9. & $\begin{array}{l}\text { Second resistance } \\
\text { terminal load, } R_{L 2, \text { stenosis }}\end{array}$ & $4.51 \times 10^{9} \mathrm{Ns} / \mathrm{m}^{5}$ \\
\hline 10. & $\begin{array}{c}\text { Capacitance terminal } \\
\text { load, } C_{L, \text { stenosis }}\end{array}$ & $3.473 \times 10^{-9} \mathrm{~m}^{5} / \mathrm{N}$ \\
\hline
\end{tabular}

Table 4: Mean flow solution of aneurysm.

\begin{tabular}{|c|c|c|}
\hline No. & Mean flow & Value \\
\hline 1. & Angular frequency, $\omega$ & $6.28 \mathrm{rads}^{-1}$ \\
\hline 2. & Womersley number, $\alpha_{2}$ & 34 \\
\hline 3. & $\begin{array}{l}\text { Resistance coefficient, } \\
c_{v 2}\end{array}$ & 6.96 \\
\hline 4. & Inertance coefficient, $c_{u 2}$ & 1.044 \\
\hline 5. & $\begin{array}{c}\text { Resistance vessel load, } \\
R_{V 2}\end{array}$ & $\begin{array}{c}1.0078 \times 10^{4} \\
N s / m^{5}\end{array}$ \\
\hline 6. & $\begin{array}{c}\text { Inductance vessel load, } \\
\qquad L_{V 2}\end{array}$ & $\begin{array}{l}3.0263 \times 10^{6} \\
N s^{2} / m^{5}\end{array}$ \\
\hline 7. & $\begin{array}{c}\text { Capacitance vessel load, } \\
\qquad C_{V 2}\end{array}$ & $2.215 \times 10^{-9} \mathrm{~m}^{5} / \mathrm{N}$ \\
\hline 8. & $\begin{array}{l}\text { First resistance terminal } \\
\quad \text { load, } R_{L 1, \text { aneurysm }}\end{array}$ & $3.6958 \times 10^{9} \mathrm{Ns} / \mathrm{m}$ \\
\hline 9. & $\begin{array}{l}\text { Second resistance } \\
\text { terminal load, } R_{L 2, \text { aneurysm }}\end{array}$ & $8.522 \times 10^{8} \mathrm{Ns} / \mathrm{m}^{5}$ \\
\hline 10. & $\begin{array}{c}\text { Capacitance terminal } \\
\text { load, } C_{L, \text { aneurysm }}\end{array}$ & $1.6243 \times 10^{8} \mathrm{~m}^{5} / \mathrm{N}$ \\
\hline
\end{tabular}

\subsection{Pressure rate of abnormal condition at first segment}

Figure 6 and Figure 7 show the pressure rate propagation in the first segment. Figure 6 shows the atherosclerosis disease while Figure 7 aneurysm disease in femoral popliteal artery. In atherosclerosis, both value $P_{R V 1}$ and $P_{1}$ are higher than value in aneurysm. $P_{1}$ reach $5.1 \times 10^{4} \mathrm{~Pa}$ for atherosclerosis and $1.0 \times 10^{4} \mathrm{~Pa}$ for aneurysm. The pressure that moves across the first vessel resistance, $P_{R V 1}$ is $4.0 \times 10^{4} \mathrm{~Pa}$ for atherosclerosis and $0.9 \times 10^{4} \mathrm{~Pa}$ for aneurysm.

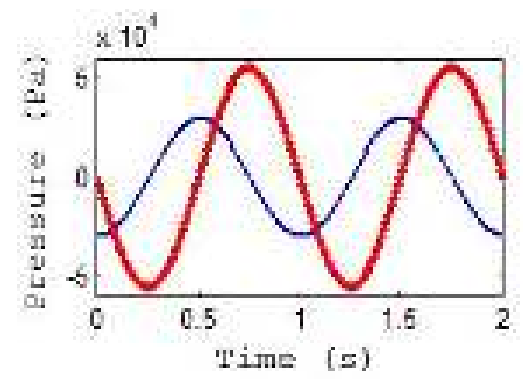

Fig. 6: Pressure rate at first segment of atherosclerosis.

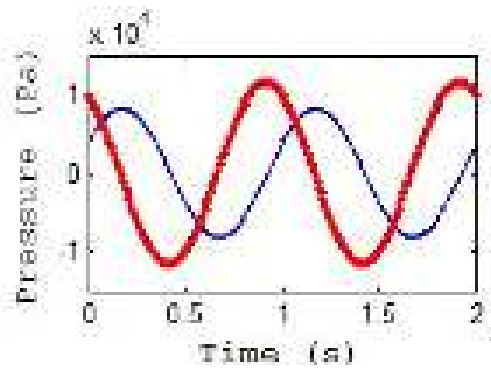

Fig. 7: Pressure rate at first segment of aneurysm.

\subsection{Pressure rate of abnormal condition at second segment}

In the second segment which is presented in Figure 8 and Figure 9, the pressure rate propagation value for atherosclerosis is $3.2 \times 10^{5} \mathrm{~Pa}$ at $P_{2}$ which is the highest peak pressure obtained from this model and approximately zeros at $P_{R V 2}$. For the aneurysm case, the value at $P_{2}$ is $0.1 \times 10^{4} \mathrm{~Pa}$ and $0.9 \times 10^{4} \mathrm{~Pa}$ at $P_{R V 2}$ the first segment.

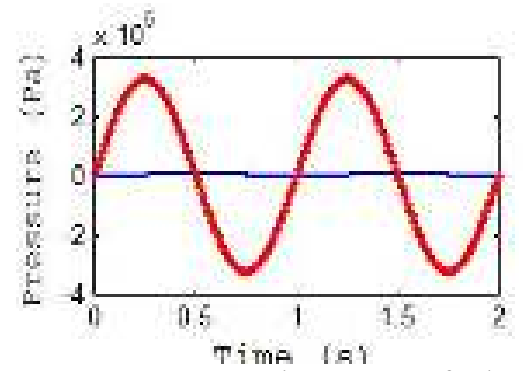

Fig. 8: Pressure rate at second segment of atherosclerosis. 


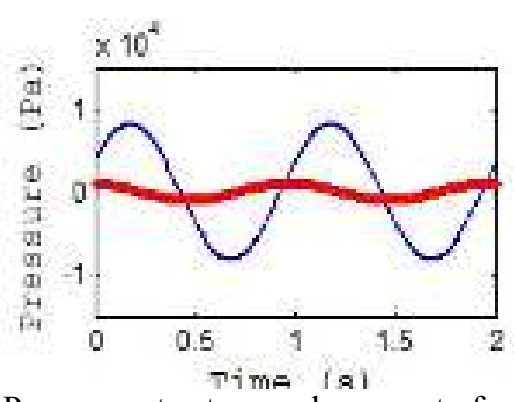

Fig. 9: Pressure rate at second segment of aneurysm.

\subsection{Pressure rate of abnormal condition at third segment and terminal load}

Figure 10 and Figure 11 show the pressure rate propagation in the third segment and terminal load segment. The pressure obtained in atherosclerosis are different with each other between $P_{3}, P_{R V 3}$ and $P_{e}$ which are is $1.9 \times 10^{5} \mathrm{~Pa}$, is $0.2 \times 10^{5} \mathrm{~Pa}$ and is $1.0 \times 10^{5} \mathrm{~Pa}$ respectively. In aneurysm, the values close to $P_{R V 3}$ and $P_{e}$ in terminal load are $0.05 \times 10^{4} \mathrm{~Pa}$ and $0.1 \times 10^{4} \mathrm{~Pa}$ respectively, but higher at $P_{3}$ which is $0.9 \times 10^{4} \mathrm{~Pa}$.

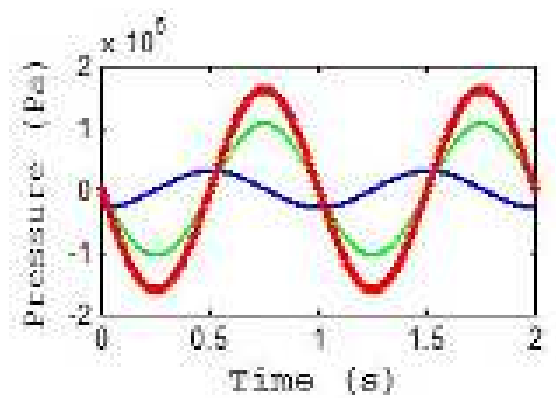

Fig. 10: Pressure rate at third and terminal load of atherosclerosis.

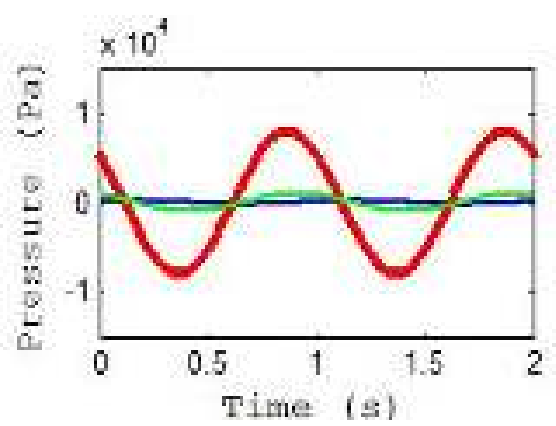

Fig. 11: Pressure rate at third and terminal load of aneurysm.

\subsection{Flow rate of abnormal condition at first segment}

Figure 12 and Figure 13 show the flow rate propagation in the first segment in both atherosclerosis and aneurysm condition. The flow rate is higher at aneurysm condition but lower at atherosclerosis condition. For $q_{1}$ in both conditions are $0.8 \times 10^{-3} \mathrm{~m}^{3} / \mathrm{s}$ and $2.6 \times 10^{-3} \mathrm{~m}^{3} / \mathrm{s}$ for atherosclerosis and aneurysm respectively. Flow that across the first capacitor, $C_{1}$ is lower at these two conditions.

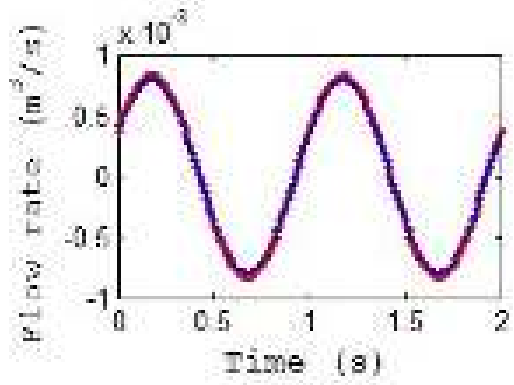

Fig. 12: Flow rate at first segment of atherosclerosis.

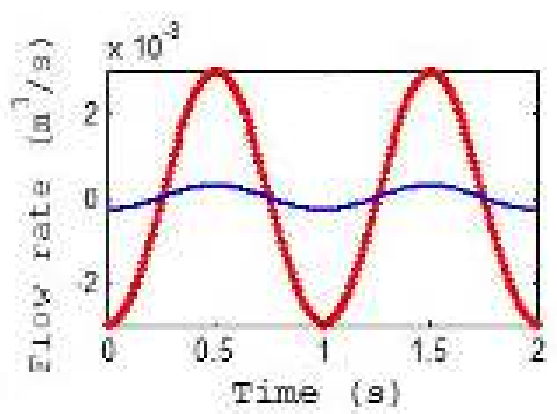

Fig. 13: Flow rate at first segment of aneurysm.

\subsection{Flow rate of abnormal condition at second segment}

As the blood flow continues, the value of flow rate, $q_{2}$ is decreases to $0.01 \times 10^{-3} \mathrm{~m}^{3} / \mathrm{s}$ in atherosclerosis. This value show the same pattern as the flow that move across the second resistor, $q_{c 2}$. In aneurysm condition, the values are the largest value obtained in flow rate value at all segments which is $3.0 \times 10^{-3} \mathrm{~m}^{3} / \mathrm{s}$. This result showed in the Figure 14 and Figure 15.

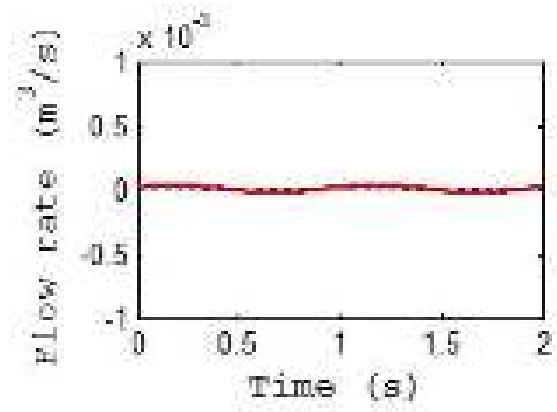

Fig. 14: Flow rate at second segment of atherosclerosis.

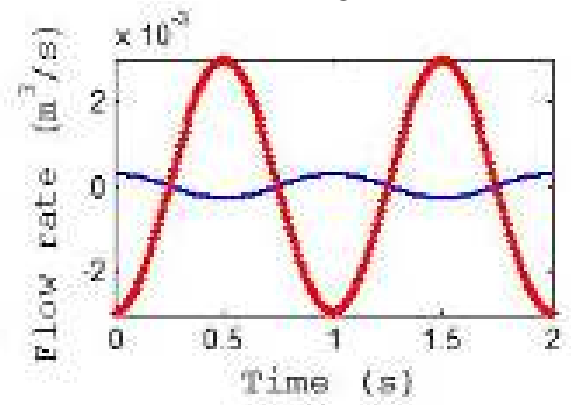

Fig. 15: Flow rate at second segment of aneurysm. 


\subsection{Flow rate of abnormal condition at third segment}

In the third segment of atherosclerosis condition, the value of flow rate $q_{3}$ is $0.09 \times 10^{-3} \mathrm{~m}^{3} / \mathrm{s}$ while $q_{c 3}$ is $0.4 \times 10^{-}$ ${ }^{3} \mathrm{~m}^{3} / \mathrm{s}$. On the other hand, the flow rate values for both $q_{3}$ and $q_{c 3}$ in aneurysm condition are $2.9 \times 10^{-3} \mathrm{~m}^{3} / \mathrm{s}$. This can be observed from Figure 16 and Figure 17.

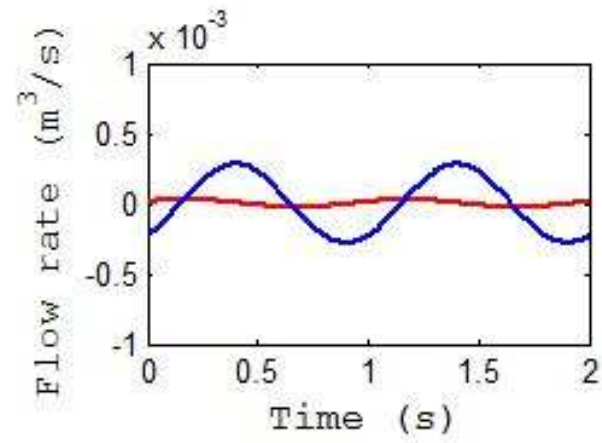

Fig. 16: Flow rate at third segment of atherosclerosis.

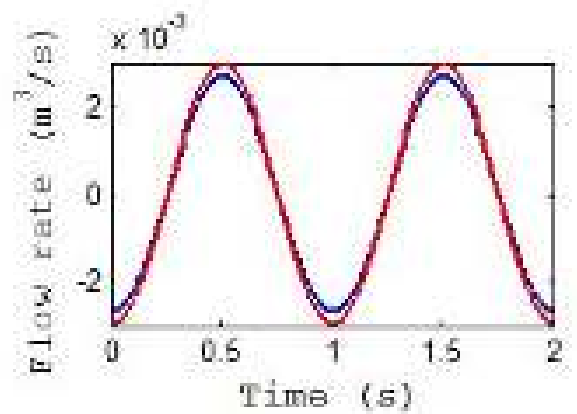

Fig. 17: Flow rate at third segment of aneurysm.

\subsection{Flow rate of abnormal condition at terminal segment}

Figure 18 and Figure 19 show the last terminal for this model which is called a terminal load segment. Both conditions obtain a huge different in flow rate result. For atherosclerosis condition, $q_{R L 1}$ and $q_{C L}$ shows $3.0 \times 10^{-3}$ $\mathrm{m}^{3} / \mathrm{s}$ while $q_{R L 2}$ values approximately reaching zero. However, aneurysm condition shows different peak variable for each flow rate of $q_{R L 1}, q_{R L 2}$ and $q_{C L}$ about $1.0 \times 10^{-4} \mathrm{~m}^{3} / \mathrm{s}, \quad 4.0 \times 10^{-4} \mathrm{~m}^{3} / \mathrm{s}$ and $3.9 \times 10^{-4} \mathrm{~m}^{3} / \mathrm{s}$ respectively.

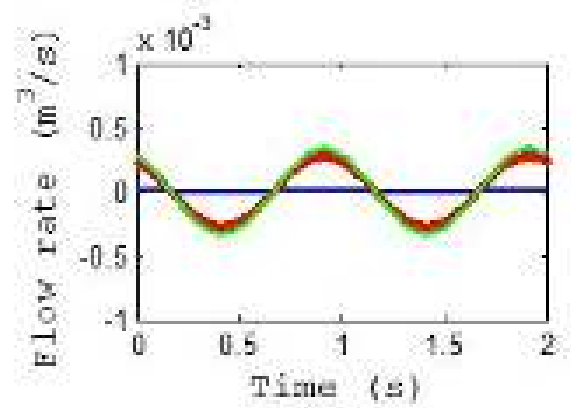

Fig. 18: Flow rate at terminal load of atherosclerosis.

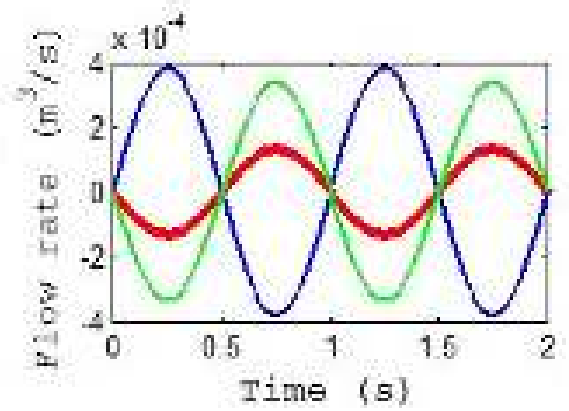

Fig. 19: Flow rate at terminal load of aneurysm.

\subsection{Discussion on analysis for normal and abnormal condition}

A linear analysis of the $0-\mathrm{D}$ system in the 2 second time domain has allowed us to identify the effects of the parameters of the outflow 0-D models on arterial pulse waveforms of pressure and flow rate. In particular, we have shown that peak pressures and flow waveforms distributions in large arteries depend on the resistances of the system once a periodic state is reached. Peripheral inertias have a minor effect on flow waveforms under all conditions. The time constant of the diastolic pressure decay is the same at 1-D model artery, the viscous dissipation and frequency in this study are considered to be constant. Therefore the result obtain in these femoral popliteal artery depends more on the peripheral compliances and resistances of the system.

Pressure obtained as a force act to the surface area at a certain object. A large the surface area gives a low pressure. Thus, the waveforms that show in the result have high and low peak value. In the human cardiovascular system, the high mean represent the systolic pressure where the contraction of artery occur then the start of relaxation of artery called diastolic for the low peak value. The different conditions in femoral popliteal artery show the different pressure waveform obtain. In the normal femoral popliteal artery, the waveform pattern show the uniform pattern almost at all difference pressure in each of every segment including the terminal load. The peak pressure rate for normal condition is $1.7 \times 10^{4} \mathrm{~Pa}$. The overall arterial waveforms seem to be the same because of the same arterial radius along the segment from first until third segment which is $3.5 \mathrm{~mm}$. Therefore, the pressure rate values are uniform as it passes through the same value of vessel and terminal resistor. The Figure 20 (a) shows the result for full pressure rate in normal femoral popliteal artery.

In the femoral popliteal artery with stenosis condition, the value of the arterial peak pressure is obviously different with the normal condition. As the atherosclerosis occur, the diameter of artery getting small. By changing the diameter of a second segment while maintaining the diameter in other segment in the electric analog model of a lumped parameter, the value of vessel resistance and capacitance will be increases. As shown at Figure 20 (b), node 2 shows the highest peak achieved by this condition which is $3.2 \times 10^{5} \mathrm{~Pa}$. If the central arteries are diameter decreases, as often occurs with peripheral 
vascular atherosclerosis, then the pulse pressure will be greater than if it were normal.

Differently with aneurysm condition that highly complaint central arteries have a low pulse pressure. The data show that at the second segment with $3.0 \mathrm{~cm}$ radius have a peak pressure $0.1 \times 10^{4} \mathrm{~Pa}$ as shown in Figure 20 (c).

Flow rate obtained in three different condition are also affected by the diameter of the artery change at the second segment. Basically, the relationship between vascular flow, the pressure difference, and resistance prove the overall result. The normal condtion have a value of $1.6 \times 10^{-3} \mathrm{~m}^{3} / \mathrm{s}$ at the $q_{1}$ where the blood flow at the first node as shown in figure 21 (a). The value not have a huge different until blood flow continuously reach the terminal load which the $q_{R L 1}$ value approximately reach zero.

Note that a small change in artery radius will have a very large influence to the resistance. As the radius of second segment in atherosclerosis condition reduce from $3.5 \mathrm{~mm}$ to $1.4 \mathrm{~mm}$, it will increase its resistance to flow by approximately 16 fold. Consequent from this increment, the flow rate at this segment will reduce drastically. The $q_{2}$ value have a peak flow rate of $0.9 \times$ $10^{-3} \mathrm{~m}^{3} / \mathrm{s}$. In the aneurysm condition, the opposite case will occur as the second segment of electrical analog model in femoral popliteal artery experience a reduction of artery diameter. Then, a high value of flow rate obtain by the $q_{2}$ which is $3.0 \times 10^{-3} \mathrm{~m}^{3} / \mathrm{s}$ as shown in Figure 21 (b) and (c).

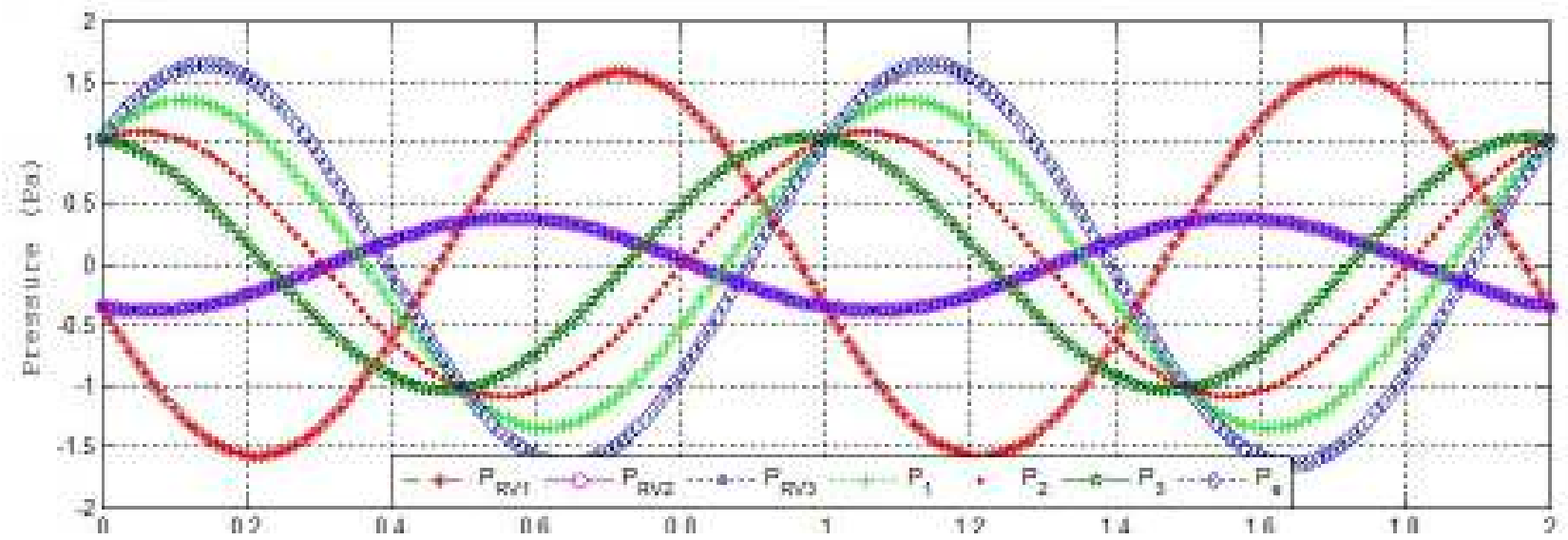

(a)

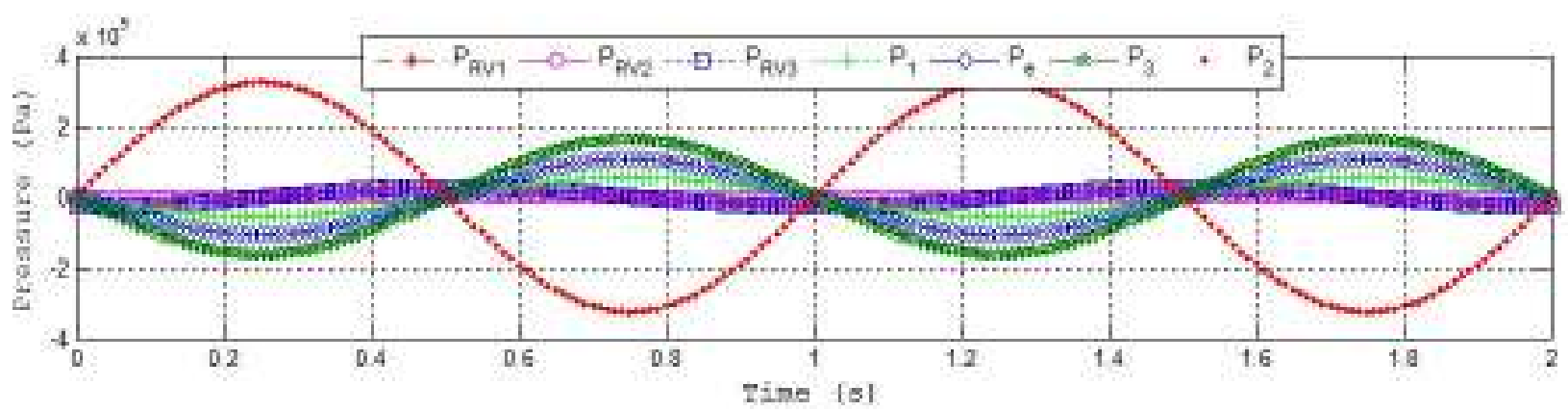

(b)

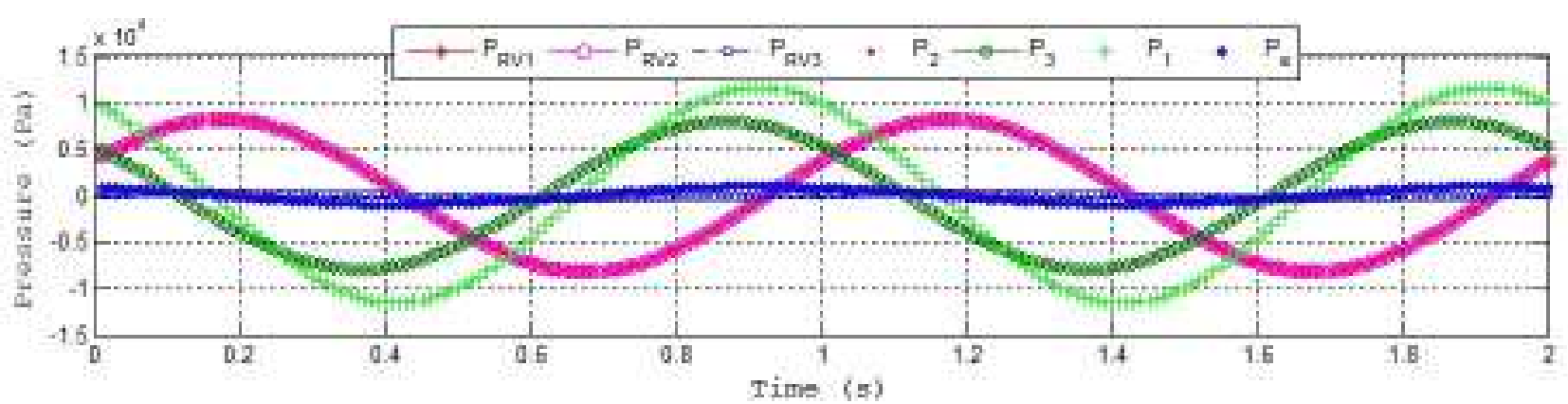

(c)

Fig. 20: The full result of pressure rate in (a) normal (b) atherosclerosis (c) aneurysm femoral popliteal artery. 


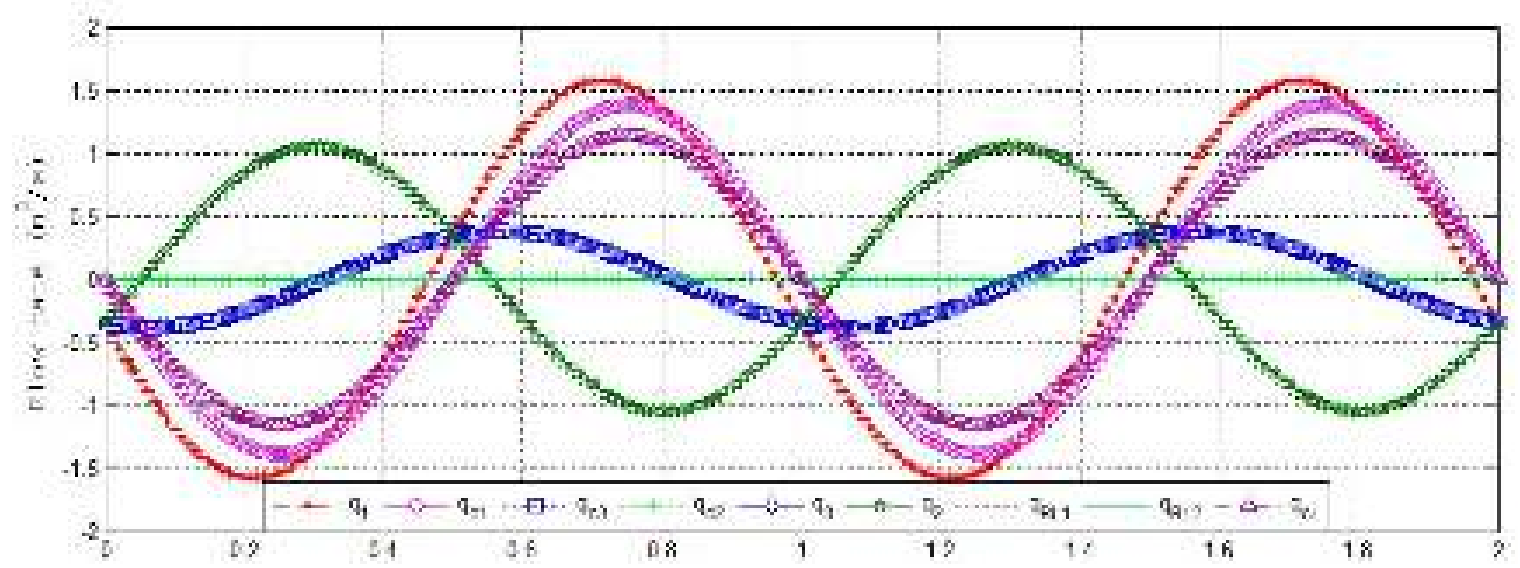

(a)

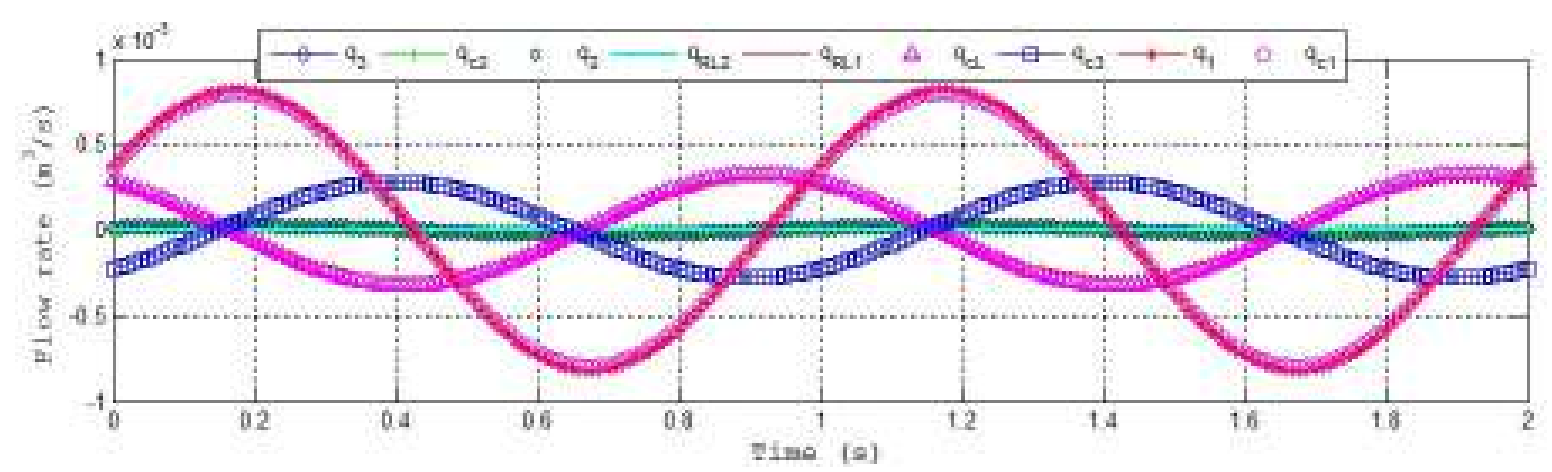

(b)

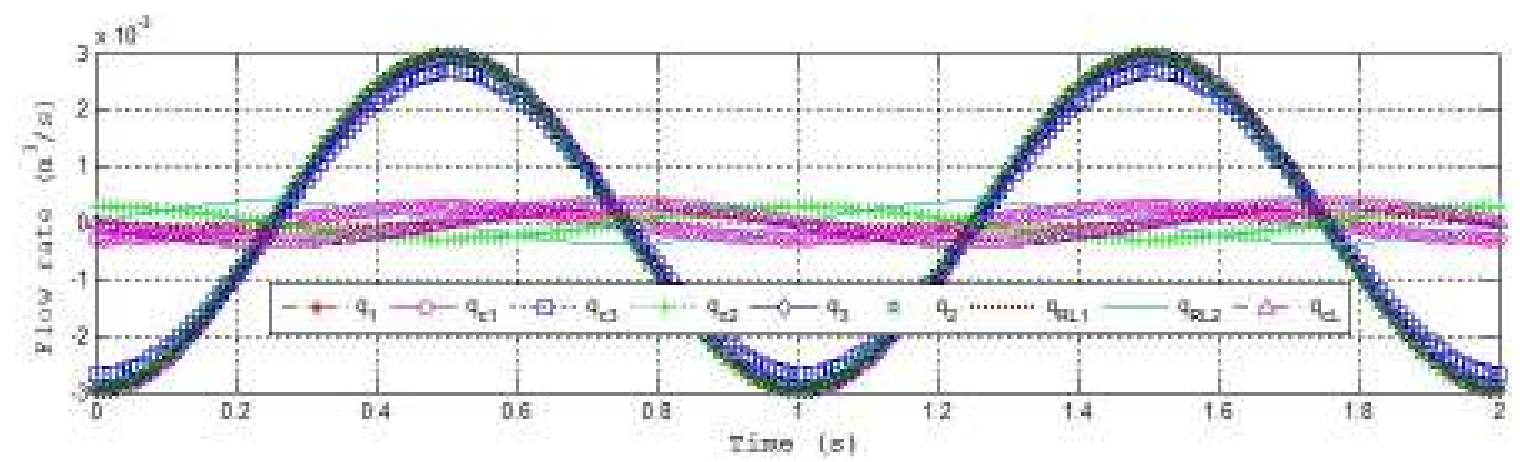

(c)

Fig. 21: The full result of flow rate in (a) normal (b) atherosclerosis (c) aneurysm femoral popliteal artery.

\section{Conclusion}

The 0-D model called lumped parameter models has been implemented and the effect of their parameters on waveform patterns in normal and abnormal condition of femoral popliteal artery has been studied. By studying the characteristics and the haemodynamics of femoral popliteal artery, a computational modelling called lumped parameter mathematical model is used to investigate the effect to femoral popliteal artery. Three electrical analog model of simplified femoral popliteal artery are modelled using resistor, inductance and capacitance. These three different models construct according to the condition of femoral popliteal artery which is normal, atherosclerosis and aneurysm. Electrical analog model that have been construct contain three segments. The ideas are by changing the arterial diameter and capacitance value for atherosclerosis and aneurysm while maintaining it for the normal condition.

At the end of this study, the computational modelling in femoral popliteal artery has been successfully conducted. After make a comparison of the data obtain between normal and abnormal flow behaviour, it can be said that the computational modelling of lumped parameter is validated. There are two haemodynamic parameter that are considered to be analyse which are pressure and flow rate. Based on the analysis that has been made through the blood flow in the second segment, the pressure rate and flow rate obtain in normal condition in femoral popliteal artery are $1.7 \times 10^{4} \mathrm{~Pa}$ and $1.7 \times 10^{-3}$ $\mathrm{m}^{3} / \mathrm{s}$. In different condition, the pressure rate is higher in atherosclerosis and lower in aneurysm condition which 
are $3.2 \times 10^{5} \mathrm{~Pa}$ and $1.2 \times 10^{4} \mathrm{~Pa}$ respectively. The objective of this study has been successfully achieved from the effects of different disease condition with differing amounts of flow and pulsatility and found the model to be useful for a realistic simulation of different perfusion regimens. Based on the computational that have been done, the findings can be described as the pressure rate and flow rate are depends on the fluid resistance from the artery itself. It can be concluded that quantitative variations of blood pressure and flow waveforms along the arterial of femoral popliteal artery from this model followed clinical trends as the normal condition show a stable pressure and flow rate obtained compare to the atherosclerosis and aneurysm condition.

\section{Acknowledgement}

This work was funded by University Tun Hussein Onn Malaysia (UTHM), under Fundamental Research Grant Scheme (FRGS) Vot 1592.

\section{References}

[1] Ottesen, J. T., Olufsen, M. S. and Larsen, J. K. Applied Mathematical Models in Human Physiology. Siam Publication, (2004), pp. 91-153.

[2] Burattini, R. and Natalucci, S. Complex and frequency-dependent compliance of viscoelastic windkessel resolves contradictions in elastic windkessel. Medical Engineering and Physics, Volume 20, (1998), pp. 502-514.

[3] Avolio, A. P. Multi-branched model of the human arterial system. Medical and Biological Engineering and Computing, Volume 18, (1980), pp. 709-718.

[4] Milisic, V. and Quarteroni, A. Analysis of lumped parameter models for blood flow simulations and their relation with $1 \mathrm{D}$ models. ESAIM: Mathematical Modelling and Numerical Analysis, Volume 38, No. 4, (2004), pp. 613-632.
[5] Westerhof, N., Bosman, F., De Vries, C. J. and Noordergraaf, A. Analog studies of the human systemic arterial tree. Journal of Biomechanics, Volume 2, (1969), pp. 121-143.

[6] Noordergraaf, A., Verdouw, P. D. and Boom, H.B.K. The use of an analog computer in a circulation model. Progress in Cardiovascular Diseases, Volume 5, (1963), pp. 419-439.

[7] Nesbitt, E., Schmidt-Trucksass, A., Il'yasov K. A. Weber, H., Huonker, M., Laubenberger, J., Keul, J., Hennig, J. and Langer, M. Assessment of arterial blood flow characteristics in normal and atherosclerotic vessels with the fast Fourier flow method. MAGMA, Volume 10, No. 1, (2000) pp. 2734.

[8] Crawford, D. W., Barndt R. J. and Back, L. H. Surface characteristics of normal and atherosclerotic human arteries including observations suggesting interaction between flow and intimal morphology, Journal of Technical Methods and Pathology, Volume 34, No. 5, (1976), pp. 463-470.

[9] Strandness, D. E. (1993). Duplex scanning in vascular disorders $\left(2^{\text {nd }}\right.$ ed). New York: Raven Press.

[10] Ibrahim, N., Mutalib, F. L. and Sari, S. Affecting Factors of Weight and Gender on Carotid Arterial Wall Motion: Diameter and Displacement Assessment. International Journal of Integrated Engineering, Volume 9, No. 3, (2017), pp. 7-10.

[11] Harun, N. H. 'I. M., Ibrahim, N., Zakaria, W. N. W., Fuad, N. F. N. and Aziz, N. S. Study of Vessel Conditions in Different Categories of Weight for Early-Stage of Deep Vein Thrombosis (DVT) Diagnosis. International Journal of Integrated Engineering, Volume 6, No. 3, (2014), pp. 57-64.

[12] Gul, R. Mathematical Modeling and Sensitivity Analysis of Lumped-Parameter Model of the Human Cardiovascular System, PhD Thesis. Berlin: Freien Universitat Berlin. (2016). 